\title{
Placemaking in Planning: A simple buzzword or a new planning movement?
}

\author{
By Matthew Goebel
}

\begin{abstract}
This article is an investigation into the role of placemaking in the modern planning profession, with a focus on the evolution of placemaking, evaluation through the lens of a case study in Edmonton, $A B$, and analysis through three planning theories. It is argued that the ideas of placemaking have existed for much longer than the word itself. A brief background is provided detailing the development of placemaking. Examples of placemaking throughout history are discussed with a focus on the writings of Jane Jacobs. The Imagine Jasper Avenue and Experience Jasper Avenue pilot projects are explored, with a discussion of their placemaking elements. The history of Jasper Avenue as Edmonton's main street and efforts to reimagine Jasper Avenue in the face of intense public scrutiny are investigated. Finally, placemaking is analysed through three planning theories: Planning as Design, the theories of Michel Foucault, and Semiotics. The major themes of these theories and their application to both placemaking and the case study are examined.
\end{abstract}

\section{Introduction}

"Placemaking" is the new favourite buzzword of the professional planning world. It has effortlessly lumped together some of the major tenets of planning-design, functionality, creativity, etc.and provided everyone from new planning graduates to the engineer-come-planners of yesteryear with an exciting "in vogue" term to relate ambitious and often expensive ideas to an increasingly wary public. As both a theoretical framework and tangible approach for improving a neighbourhood, city, or region, "placemaking inspires people to collectively reimagine and reinvent public spaces as the heart of every community" (Project for Public Spaces (PPS), 2009c). The idea of placemaking frequently appears in many contemporary documents concerning the creation of new neighbourhoods or the reimagining of downtowns in need of a renewal. Yet, it is not a new idea; the groundbreaking 1961 treatise The Death and Life of Great American Cities by planning champion Jane Jacobs established the ground rules for a place-based, community-centred approach to urban planning decades before those ideas were considered acceptable or popular by the professional planning society (PPS, 2009c). Indeed, it was arguably Jacobs' most valuable work to promote the places so often threatened by the predominant planning theories of her time. Even then, it is not as if the planners of the 19th and early 20th centuries did not embrace the idea of 'turning space into place' in their monumental buildings and large-scale redesigns (or upheavals) of entire cities, such as in Haussmann's rebuilding of Paris. As these efforts show, the ideas of placemaking have been present for decades, and so the question arises: why has there been a sudden renaissance of the ideas of placemaking in professional planning?

In an attempt to answer the above question, and comprehend the overall nature of the following case study and topic, this paper will examine the history and fundamentals of placemaking, reviewing the placemaking 
ideas of Jane Jacobs from more than 50 years previous, and introducing ideas from one of the foremost leaders in current placemaking best practices, the Project for Public Spaces. It will then discuss the Imagine Jasper Avenue concept design and Experience Jasper Avenue pilot project in the City of Edmonton, a redesign of the city's premier street running through not only the physical, but also psychological heart of Edmonton. This paper will explore the common themes that are shared between placemaking and the main goals of the Imagine Jasper Avenue project. It will then discuss the successes and failures of the pilot project itself, known as Experience Jasper Avenue, referring back to ideas of placemaking. This paper will then describe the creation of a new theory and apply it to both the topic and case study. First, 'Planning as Design' will be considered, investigating the pros and cons of allowing professional planners to redesign a street that has historically functioned as a major automobile thoroughfare into a place for all Edmontonians to comfortably gather as pedestrians. The ideas of respected scholar Michel Foucault will be discussed, with a particular focus on Foucault's ideas of societal trends and the power dynamics influencing our day-to-day decisions. Finally, the ideas of semiotics will be applied in order to understand the extremely symbolic nature of the Imagine Jasper Avenue project as a sign of maturation of the city as a whole, and the methods used to show Edmontonians that their main street is being reclaimed as a place for pedestrians.

\section{Public vs. Private Spaces}

The ever-increasing spread of suburban development has created for many city dwellers a hopeless feeling of entrapment inside a "labyrinthine network of power and disempowerment" (Friedmann, 2010, p. 150). This is to say that the very nature of our most predominant urban form today, the sprawling repetition of suburban housing developments and commercial strip malls found especially within the North American context, fosters a disconnection of urban citizens from their environment. On the flip side, what Friedmann (2010) calls "megaprojects", such as Dubai's Buri Khalifa superskyscraper, often attempt to "brand their cities, as if cities were a commodity for sale" (p. 150). These mega-projects strive to create a unique identity and magnificent sense of place, yet fail to consider "the needs of ordinary people and the neighbourhoods they inhabit" (Friedmann, 2010, p. 150), and thus do just as much to destabilize the sense of place which ties communities together as that of the repetitive suburban form.

This dueling dichotomy of placeless urban form competing against the over-achieving mega-project has a long and complex history beginning with the trend towards urbanization as a result of the Industrial Revolution. Friedmann (2010) posits that the 21 st century "will be seen as the concluding chapter of a three centuries-long saga" (p. 149) of urban transition, where at the end of the 18th century urban population stood at less than $10 \%$ globally, current projections suggest a rise to $70 \%$ global urban population by 2050 . Indeed, the acceleration of the growth of urban citizens worldwide is happening "even as nation states... lose control over urban policy, having devolved substantial powers for managing urban growth to local governments" (Brenner, 2004, as cited in Friedmann, 2010, p. 150). Of course, as local governments must deal with their rapidly increasing urban growth alone, the resources at their disposal often fail to grow accordingly. Therefore, it is much easier to simply repeat proven and mundane infrastructure developments over and over again as population increases, and only occasionally attempt placemaking mega-projects in a vain attempt to bring a unique identity to the local community. There is a 'missing middle' when it comes to placemaking in urban development.

As a result of intense competition for the rapidly urbanizing citizens and the increase in capital that they provide, local governments have successfully shed many of their newfound responsibilities onto the private sector "as [local] governments, eager to capture the attention of potential investors, turn entrepreneurial themselves, hoping their cities will reach worldclass status through public-private partnerships 
essentially geared towards profits" (Friedmann, 2010 , p. 150). This has caused an explosion of private space at the expense of public space (Friedmann, 2010), whereby previously community-minded places, such as pedestrianscaled public parks or farmers' markets have been replaced with privately-owned spaces, such as grandiose sporting arenas or enormous shopping malls. These privately-owned spaces attempt to serve the same purpose as a public place and create a unique sense of community, but they are all too frequently locked behind closed doors, requiring a hopeful citizen to prove their worth with access to sufficient funds, or perhaps even worse, are easily repeated in any urban location in which they happen to occur with no lasting semblance to the conurbation that they are supposed to represent.

\section{The Ideas of Jane Jacobs}

In his essay investigating the writings of Jane Jacobs, David Seamon (2012) contends that Jacobs' Death and Life of Great American Cities can be interpreted as a phenomenology of the city and urban place. In terms of "method, focus, and discoveries," Seamon (2012, p. 139) posits that Jacobs' understanding of the city can be described as a concept that he refers to as 'citiness'. In other words, Seamon feels that in writing Death and Life, Jacobs captures the very essence of what makes a city a place in which people actually live, not simply a collection of people in dwelling units. This is what placemaking is all about!

In Death and Life, Jacobs argues that mid20th century urban design and city planning undermined the urban fabric of the American city because planning professionals "understood the phenomenon of a city not as it actually was but as professionals wanted it to be" (Seamon, 2012, p. 139). The 'towers in the park' concept of Le Corbusier and Robert Moses' "megablock urban renewal policies and massive highway construction" (Seamon, 2012, p. 140) are used as examples, among others. These ideas formed after Jacobs saw firsthand the "urban renewal projects that she realized... were dramatic failures as livable places and communities" (Seamon, 2012, p. 140). It is this contrast between the failure of the urban renewal projects supported by established planners of her time and Jacobs' own successful, animated, and diverse neighbourhood of Greenwich Village, considered by her contemporaries to be of little importance, that would lead Jacobs to her understanding of urbanity that "was grounded in what the city and urban experience actually are: a lived diversity of place that sustains personal and group identification and attachment" (Seamon, 2012, p. 140).

From this perspective, Jacobs realized that the most successful urban neighbourhoods do not take for granted the unique social and cultural environment found within them (Seamon, 2012). With this in mind, Jacobs argued that the most robust neighbourhoods fostering the strongest diversity and sense of place are those that arise organically because they want to, not because they are forced. It is this kind of organic urban form that because of its "vitality... draws residents, visitors, and other users who feel attachment and belonging for that place" (Seamon, 2012, p. 141). Jacobs recognized that urban citizens were molded by the environment in which they lived. In particular, the combination of "short blocks; a range of building types; a high concentration of people; and a mixture of primary uses" (Seamon, 2012, p. 142) were the physical features that created a high probability of the sense of place that was so desperately trying to be created through the urban redevelopment projects of her day.

\section{Placemaking Best Practices}

In researching ideas and sources for this paper, the Project for Public Spaces (PPS), a nonprofit planning, design, and educational organization concerned with placemaking, proved to be an extremely valuable resource. Founded in 1975 to expand upon the work of renowned scholar William $\mathrm{H}$. Whyte, the mission statement of PPS is to help urban citizens "create and sustain public spaces that build stronger communities" (PPS, 2009a). PPS has 
published hundreds of articles that all relate to placemaking, but a few stand out as they relate particularly well to the case study that will be discussed shortly. In discussing these articles, it is hoped that the reader will recall the ideas mentioned here when considering the case study.

Most of our main streets, especially within a North American context, are 'broken'. That is not to say that they are in physical disrepair, but rather that they do not serve their original purpose successfully. While streets were once a place for people to enjoy as pedestrians, they are now predominantly a means to an end for quick travel from one place to another primarily by private automobile (PPS, 2014). This was a deliberate change over time, pushed in part by planners attempting to react to the ever-expanding traffic demand and increasingly suburban nature of our cities. Indeed, urban streets "typically represent the largest area of public space that a community has" (PPS, 2009b). In Chicago, for example, publicly owned streets and sidewalks represent $24 \%$ of the city's total land area and more than $70 \%$ of all city-owned public open space (PPS, 2009b). PPS (2009b) claims that with the introduction of select placemaking ideas, urban streets can become the "critical public spaces that... lend richness, to the social, civic, and economic fabric of our communities."

The first suggestion of the PPS (2014) is to plan for other transportation forms. A successful transportation network which provides for alternative forms of transportation, such as bicycling or public transportation, is "a means for accomplishing important goals - like economic and productivity and social engagement - not an end in itself" (PPS, 2014). The most successful pedestrian paradises, with an undeniable and immediately apparent sense of place, are those which allow their citizens access without the use of a private automobile; PPS (2014) uses the amazing rail transportation facilities of Grand Central Terminal in New York City and the wide sidewalks of the Champs Elysées in Paris as definitive examples of walkable areas with a strong sense of place. Designing alternative transportation networks to fit into the community context and the existing road network can link individual communities together, reduce household dependency on the automobile, connect far-flung suburban areas to vibrant downtowns, and build healthier lifestyles by increasing the potential to walk or cycle (PPS, 2014). Placemaking is about the public benefit, not just private convenience.

The second suggestion of the PPS (2014) is to design our main streets for the appropriate speed. Currently, most of our streets are designed to allow the maximum amount of automobile throughput possible. But it is not enough to change the legal speed limit of a street, since more often than not, the legal speed limit of a street is considered more of a suggestion than a hard rule to follow. Instead, changes in the actual physical design of our streets must be implemented, such as the roadway width, curvature, and intersection design (PPS, 2014). "Roadside strategies, like building setbacks and (increased) sidewalk activity, can also impact the speed at which a motorist will comfortably drive" (PPS, 2014). PPS rightly claims that no one can visit a store from their speeding car; high speed automobile traffic will nullify even the most successful placemaking strategies.

The final suggestion of the PPS (2014) is to think of streets themselves as public space. To many of Jane Jacobs' contemporaries, this would have been a preposterous notion- public space was reserved for parks and little else. But this idea is the crux of Jacobs' (1961) argument: that the physical space of a community can become a place. Sidewalks and bus stops can be more than something to walk on or a place to wait. Streets are not just simply "conduits for cars" (PPS, 2014), they can become places all their own. With a little imagination, everyday infrastructure can become something worth visiting. To the PPS (2014), "transportation is the journey, but enhancing the community is always (the) goal".

\section{Imagine Jasper Avenue and Experience Jasper Avenue}

Beginning construction in 2019, the Imagine Jasper Avenue project is an initiative by the City of Edmonton to reimagine the city's main street, 
Jasper Avenue, as an "innovative, vibrant, and relevant streetscape that will strive to balance the needs of the community, commuters, businesses, and visitors" (City of Edmonton, 2017). The idea to entirely overhaul the design of Jasper Avenue is grounded in pure cost-effective engineering; in the early 2010s, city officials realized that the aging infrastructure along most of the main street had reached the end of its serviceable lifespan and would have to be replaced (ISL Engineering and Land Services, 2017). Instead of simply rebuilding the existing infrastructure as it currently exists, the City of Edmonton wisely recognized that Jasper Avenue could be redefined as a dynamic, multi-purpose space that would ensure the "safe and efficient flow of multiple transportation modes through the corridor" (ISL Engineering and Land Services, 2017). While of course being strongly influenced by the current best practices within the professional planning industry and technical standards and studies, the Imagine Jasper Avenue project also incorporated a large amount of public consultation from business leaders and citizen stakeholders, who meaningfully contributed to the final design decisions of the overall project (City of Edmonton, 2017). Through public engagement sessions, city officials worked together with the public to develop a vision and guiding principles for the redesign of Jasper Avenue, "determining priorities and trade-offs, selecting options for alternative design possibilities and providing considerations for all user types in the development of the final design" (City of Edmonton, 2017). When combined with the other redevelopment initiatives in the neighbourhoods surrounding Jasper Avenue and within the entire downtown area, such as the development and expansion of bike lanes and routes, extension of light-rail transit, and rebuilding of similar main streets, it is hoped that a fundamental transportation mode and urban identity shift will occur within downtown Edmonton (ISL Engineering and Land Services, 2017).

Over its history as one of Edmonton's oldest streets, Jasper Avenue has accommodated a variety of transportation modes, from stagecoaches and wagons to streetcars and trolleybuses (ISL Engineering and Land Services, 2017). Today, Jasper Avenue is currently an almost entirely automobile-focused street, with private transportation options "consum[ing] the available right-of-way, and restrict[ing] pedestrian and cyclist activities" (ISL Engineering and Land Service, 2017) along its entire extent. In response to this perceived deficiency, the Imagine Jasper Avenue project presents a unique city-building opportunity "to develop an improved balance between pedestrian, transit, cycling, and vehicular traffic accommodations" (ISL Engineering and Land Services, 2017) while revitalizing the neighbourhoods surrounding Jasper Avenue and supporting increased redevelopment, such as new commercial properties and infill housing. A number of priorities were identified as necessary inclusions by stakeholders, business leaders, and City of Edmonton officials to be included in the final form of the revitalized Jasper Avenue, such as: prioritization of pedestrians through improvements to pedestrian safety, convenience and amenities in the form of increased sidewalk widths, traffic speed reductions, etc.; changes to roadway design and intersection function, or changing traffic interactions between vehicles, pedestrians, and cyclists, including reduction in automobile traffic lanes from three throughlanes in each direction to two through-lanes in each direction; and public space improvements, including the potential for placemaking elements alongside the reinforcement of the community identity of Jasper Avenue (ISL Engineering and Land Services, 2017).

As part of the Imagine Jasper Avenue project, Jasper Avenue will be the first street in the city to be redesigned in accordance with Edmonton's 'Main Street' Guidelines (Stantec Consulting Ltd., n.d.; City of Edmonton, 2017). "Main streets are both important destinations and transportation links" (City of Edmonton, 2017); in other words, besides being corridors for the movement of people, goods, and services, real main streets are also places. Main streets are designed to give priority to pedestrians by widening sidewalks, providing additional street furniture and landscaping amenities to increase 
comfortability, and reintroducing greenery back into the street environment in the form of pocket parks or boulevard trees (Stantec Consulting Ltd., n.d.; City of Edmonton, 2017). In addition to the usual improvements described in Edmonton's Main Street Guidelines, the Imagine Jasper Avenue project will also focus on connecting with the history of the street and surrounding neighbourhoods, creating 'flex space' to allow for events and activities, such as festivals or street parties, to occur on Jasper Avenue itself, and enhancing transit service by providing increased and updated transit infrastructure, such as bus shelters and 'bus pads', or extensions to the sidewalk allowing for easier ingress and egress onto public transportation (City of Edmonton, 2017; City of Edmonton n.d.).

\section{Case Study Relationship to Placemaking}

We can plainly see that the Imagine Jasper Avenue project has a great many similarities with the placemaking guidelines set out by the Project for Public Spaces (PPS). Until the midto late-20th century, Jasper Avenue was the vibrant heart of Edmonton's bustling downtown, providing a relatively balanced amount of space for pedestrians, public transit, and private transportation. Over time, as Edmonton's population boomed and the priorities of planners changed to accommodate the increase in automobiles, so too did the physical layout of Jasper Avenue become skewed. The Imagine Jasper Avenue project will rectify this problem by reallocating space back to the sidewalks and reinvigorating the public transit infrastructure along the entire extent of the street, allowing citizens the option of enjoying Jasper Avenue entirely car free. The project will make physical design changes to the layout of Jasper Avenue, reducing travel lanes, narrowing the remaining lanes, and making other meaningful physical infrastructure changes to reduce traffic speed and increase pedestrian comfort. Perhaps most importantly, the Imagine Jasper Avenue project will rethink Jasper Avenue as a place all its own, with innovative flex space for holding public events right on the street, among other placemaking initiatives, in the hope thatJasper Avenue becomes a place to go to, not a space to pass through.

The Imagine Jasper Avenue project connects to the ideas that Jane Jacobs held about placemaking developments as discussed by David Seamon (2012). Jasper Avenue exists in its current, rather poor state because, at the time of its last major physical reconstruction in the mid20th century, automobile access to downtown from brand new suburban developments was the priority of essentially every planner in North America. Had someone like Jacobs been around to fight the removal of the streetcar lines in favour of extra automobile travel lanes, or argue against the idea that the safety and comfort of pedestrians on Edmonton's main street should be compromised for increased traffic throughput, perhaps Jasper Avenue and its surrounding neighbourhoods would be a little more like Jacobs' beloved Greenwich Village and a little less like Le Corbusier's'towers in the park' concept. However, it is important to note that the changes happening to the street under the Imagine Jasper Avenue project are under the absolute directive of the City of Edmonton. In other words, while citizen stakeholders and surrounding community members have undoubtedly had their say in the project, it is nevertheless being forced upon the public. This is in direct contradiction of Jacobs' recommendations that attachment to place happen organically and raises questions about whether the redevelopment of Jasper Avenue will have the desired natural placemaking effect.

It is also worth questioning if the Imagine Jasper Avenue project is a type of mega-project as discussed earlier in this paper. These artificial placemaking developments often fail to mesh with the surrounding 'ordinary' infrastructure and feel out of context within the city as a whole, not to mention the great monetary expense often experienced by the local government in their construction. Perhaps it would be a better use of municipal funds to take the middle ground on the reconstruction ofJasperAvenue, making additions and improvements over an increased length of time and responding to the reactions, either positive or negative, by the public who must live with the infrastructure changes. One irrefutable 
positive of the Imagine Jasper Avenue project is that it will continue as wholly public space. Open at all times of the day and every day of the year, Jasper Avenue will remain entirely free for all modes of transportation. However, with the extensive infrastructure upgrades to essentially make Jasper Avenue more presentable, there may be a certain subset of the population that the City of Edmonton, citizen stakeholders, and business leaders subconsciously wish to remove from the street, such as people who are homeless. It is important to consider that the very improvements meant to welcome Edmontonians back to Jasper Avenue might have the opposite effect on marginalized members of society.

\section{The Pilot Project}

As part of the Imagine Jasper Avenue project, a test implementation was established from July to October 2017. This pilot project, known as Experience Jasper Avenue, was designed to gauge public opinion and collect feedback on some of the proposed infrastructure changes that will eventually be made permanent under the full roll-out of the Imagine Jasper Avenue project in 2019 (City of Edmonton, n.d.). During the design demo, the existing outside lanes on Jasper Avenue, which are currently configured as bus lanes during peak traffic time and parallel parking lanes during off peak times, were closed to all vehicular traffic using temporary barriers (City of Edmonton, n.d.). The space reclaimed from traffic was then reconfigured into "additional public space in the form of 'flex space'" (City of Edmonton, n.d.). Flex space is defined by Edmonton's Main Streets Guidelines as an "ancillary zone... used to support the activity of the [surrounding neighbourhood] and help to create great people places" (Stantec Consulting Ltd., n.d, p. 6). On Jasper Avenue, the default use of the flex space was on-street parking, which was "reallocated to spaces for people rather than cars, as demand [arose]" (City of Edmonton, n.d.). Other major changes included: curb extensions at intersections; the addition of traffic signals at every intersection; and the installation of street trees and other landscaping improvements (City of Edmonton, n.d.). The positives from the Experience Jasper Avenue pilot project were highlighted almost three years later during the early stages of construction for the final design (Stolte, 2019). In the article, the massive increase to the available public space along the street is noted as an improvement by the public (Stolte, 2019). The increase in greenery provided by the addition of street trees is another commonly stated bonus (Stolte, 2019). While traffic impacts along the extent of the pilot project and a slight decrease in available street parking were observed from the removal of the two outside lanes on Jasper Avenue, these impacts were minimal and the benefit of increased pedestrian comfort and functionality far outweighed the seconds lost to automobile transportation (Stolte, 2019). While some Edmontonians commuting from their farflung suburban houses did not appreciate the increase in commute time to their downtown offices, the neighbouring communities surrounding the Experience Jasper Avenue pilot project welcomed the changes to the public realm, as they provided a direct benefit to the amenities of their neighbourhoods (Stolte, 2019). Perhaps most importantly, the Experience Jasper Avenue pilot project began a conversation in the entire City of Edmonton around the current state of Jasper Avenue and what the future holds for our main street (Simons, 2017).

Areas for improvement in the final design of the project were also investigated by the news media (Gunter, 2017; Simons, 2017). The build out of the pilot project infrastructure was subpar, with the street trees dying in their planters due to lack of water and the temporary bollards being blown over in stiff winds (Gunter, 2017). Of course, the temporary nature of the pilot project was a necessity, as every piece of infrastructure had to be able to be moved at a moment's notice in case of some unforeseen safety or other liability issue. Unfortunately, the extremely temporary nature of the Experience Jasper Avenue pilot project, such as sidewalk extensions being constructed out of rather unsightly asphalt, led to unaware citizens misunderstanding the pilot project as the finished product, and contributed to the overall negative 
reaction to the pilot project by a majority of Edmontonians (Gunter, 2017; Simons, 2017). The section of Jasper Avenue on which the pilot project was constructed is not currently a destination for most Edmontonians, with the primary nearby use being residential apartments and condominiums. There are currently very few unique activities for citizens to engage, and this contributed to the relatively poor utilization of the placemaking infrastructure constructed as part of the pilot project, such as ping-pong tables and picnic benches (Simons, 2017).

\section{Application of Theory}

The Imagine Jasper Avenue case study and placemaking can be investigated through a wide variety of theories relating to planning. I believe that Planning as Design, the theories of Michel Foucault, and Semiotics can be combined into a brand-new theory that allows for in-depth analysis of the Imagine Jasper Avenue project as it relates to the ideas and principles of placemaking.

\section{Planning as Design}

Planning as Design, placemaking, and the Imagine Jasper Avenue project fit together perfectly and share many common themes and ideas. Carmona, Magalhães, and Edwards (2002) investigated the social and environmental benefits of any project as dictated by an increase in urban design standards within the context of public participation by citizen stakeholders. The ecological footprint of a development has become increasingly prominent within Planning as Design (Carmona et al., 2002). However, the extent to which environmental sustainability should be marginalized in light of the "pressures of inter-city competition for investment, jobs, and economic activities in a globalized economy" (Carmona et al., 2002, p. 146) have forced local governments to re-examine the "contribution that well-designed and managed urban environments might make towards enhancing the economic competitiveness of [a place]" (Carmona et al., 2002, p. 146). Here, the Imagine Jasper Avenue project is perhaps flawed; the proposed changes are undoubtedly improvements to the quality of the public realm, and will increase the economic competitiveness of the area and possibly Edmonton as a whole, yet the potential for increased traffic congestion from the removal of two travel lanes raises concern. On the other hand, the Imagine Jasper Avenue project promotes the use of alternative forms of transportation, and so potential environmental concerns might be mitigated by an overall transportation mode shift by community members. The Imagine Jasper Avenue project faces opposition inherent in the "contemporary development climate" (Carmona et al., 2002, p. 146), in which there is a perception that better urban design generates costs without demonstrating overt public benefit. This has already been showcased in the Experience Jasper Avenue pilot project, whereby public realm improvements were almost immediately called out by mass media organizations without being given a chance to demonstrate the potential for placemaking improvements, and instead potential automobile traffic impacts became the largest issue.

Van Assche, Beunen, Duineveld, and de Jong (2013) explored the contributions of Planning as Design to the overall coordination of spatial organization. When the highest priority of a planning project is excellent urban design, "it is more likely that other considerations are not given much weight" (Van Assche et al., 2013, p. 188). When this situation is encountered within large urban spaces that must accommodate multiple users and uses, Planning as Design will create friction between users and eventually within the planning system itself (Van Assche et al., 2013). It also raises the question of whether the space is designed for the people who will use it or the planners and designers reacting to the latest urban design trends (Van Assche et al., 2013). One of the major criticisms of the Experience Jasper Avenue pilot project was that the placemaking elements meant to improve the public perception of the street and garner public interest were not altogether interesting, well-used, or perceived as safe by community members. Perhaps the Imagine Jasper Avenue project has fallen into a trap of design 'because it 
looks good', rather than design 'because it works for the public who will use it most'. Van Assche et al. (2013) discuss the 'subtle monopolization' of Planning as Design and its potentially sinister goal of "educating supposedly ignorant citizens in a supposedly objective design syntax" ( $p$. 191). This unfortunate turn-of-events has the result of encouraging an inefficient system that represents a "major democratic deficit" (Van Assche et al., 2013, p. 191) and which ignores "problems acknowledged elsewhere in society" (Van Assche et al., 2013, p. 191); this concludes in the powerful leaders of our society "pursu[ing] their [own] interests at the expense of the common good" (Van Assche et al., 2013, p. 191). It is quite possible that the Imagine Jasper Avenue project has fallen into this trap, whereby the promotion of this fundamental shift in the design and function of Jasper Avenue is a result of planners attempting to do what they think is best for Edmontonians, when in reality, it is a pet project for their own egos. There are multiple city-run projects that are arguably of a higher priority than a redesign of Jasper Avenue, such as funding for affordable housing or other initiatives which will directly benefit marginalized members of our society, and yet rebuilding a street which functions relatively fine as it stands will be prioritized over those other vital projects.

Cilliers and Timmermans (2012) discuss the participation of the public in the Planning as Design and placemaking processes. Planning for placemaking is inherently planning for people, but the needs of the public are constantly changing (Cilliers \& Timmermans, 2012). The complexity of the placemaking process has continued to increase due to the "increasingly dynamic (and changing) needs and preferences of society, with regard to social, sustainability, and economic issues" (Cilliers \& Timmermans, 2012, p. 414). As a result of the conflict between a "traditionally slow-changing [urban] environment" (Cilliers \& Timmermans, 2012, p. 414) and the fastchanging needs of society, there now exists a tension between what our citizens want their public space to do and what their public space actually does. The Imagine Jasper Avenue project attempts to rectify this conflict, yet has become embroiled in disagreements from all political opinions and business mindsets. Perhaps the project is attempting to make changes which many Edmontonians simply are not yet ready for; in the same vein, the public demands these changes to our urban places and our politicians expect planners to promote a fundamental shift in the transportation modes we prefer. The "traditional focus of urban planning was to plan for buildings and infrastructure, where the endproductwas to attract life" (Cilliers \& Timmermans, 2012 , p. 414), whereas the current placemaking approach is "focused on adapting spaces to people, thus emphasizing the social realities (in terms of movement patterns, behaviour patterns, interaction patterns) and needs (in terms of social structure, public places to socialize, adhering to the individual's perspective and vision)" (Cilliers \& Timmermans, 2012, p. 414). In other words, where placemaking once focused on building places, it now focuses on molding spaces into places that people want to enjoy. The Imagine Jasper Avenue project fully embraces this new form of placemaking; planners gathered the opinions of the public, investing significant time into attempting to change the basic concept of what Jasper Avenue means to Edmontonians. In this way, I believe the upcoming redesign of Jasper Avenue will be increasingly accepted over time, and we will one day marvel at how inhospitable our main street once was.

\section{Theories of Michel Foucault}

Investigating the Imagine Jasper Avenue project and its placemaking themes through the lens of Michel Foucault allows the ideas of power dynamics, knowledge and truth, and trends to be applied to the new theory being created in this paper. Richardson (1995) explored the implications of Michel Foucault's work on discourse, knowledge, and power for understanding planning theory. For Foucault, modern power "is relations of power not visibly emanating from a sovereign source but masked as forms of truth and knowledge" (Richardson, 1995, p. 281). In our field of study, the "agents of this normalizing and disciplinary" (Richardson, 
1995, p. 281) form of power relations are recognized as "planners, policy analysts and researchers, and politicians... [and also] the citizens who internalize the codes and values of particular power regimes" (Richardson, 1995, p. 281). It is these inescapable power relations that mould the places we live within. Foucault's "Rule of Immanence" (Foucault, 1988) explains that "power is not imposed on individuals... but instead is immanent in 'local centres', such as the relations between agents (planners, interest groups) and citizens" (as cited in Richardson, 1995 , p. 282). It is extremely feasible to hypothesize that the physical form of the Imagine Jasper Avenue project is a result of these power relations. During public engagement sessions, planners and citizens would have deliberated on the pros and cons of the proposed changes to Jasper Avenue, making concessions, additions, and subtractions until finally reaching a consensus on the proposed changes in their current iteration. Of course, the planners would have had a more formalized power dynamic, along with having the backing of the City of Edmonton to carry out this project essentially regardless of public opinion as a result of the reconstruction of Jasper Avenue being required due to ageing infrastructure. Nevertheless, the poststructuralist shift of our 21 st century society would have provided citizens with their own power to influence the Imagine Jasper Avenue project, as they are ultimately the 'leaders' of the City of Edmonton.

To Foucault, knowledge and truth are a function of power (Richardson, 1995). "Policy analysts and planners have frequently claimed that their work is based on rationality and objective reason" (Richardson, 1995, p. 282). This idea is otherwise known as 'facts', and "are generally supported by claims to rationality" (Richardson, 1995, p. 282). In modern Western society, 'truth' is "centred on the form of scientific discourse and the institutions which produce it" (Foucault, in Fontana \& Pasquino, 1991, p. 51, as cited in Richardson, 1995, p. 282). Foucault breaks down the barrier between the natural and the social sciences, arguing that truth is socially produced (Richardson, 1995). It is a fact that most Edmontonians are satisfied with the existing layout of Jasper Avenue; any basic opinion poll would tell you that more citizens prioritize easy automobile access than pedestrian comfort and placemaking amenities. But it is interesting to study this 'fact' through Foucault's idea that what is currently accepted as 'truth' might be little more than a socially produced power relation that has formed over time as a result of the attachment of Edmontonians to their private automobiles. It is highly probable that this current truth will change as the priorities and opinions of Edmontonians change. Therefore, I believe that it is in the best interest of the City of Edmonton to do exactly what they currently plan to do: push forward with currently unpopular placemaking changes to the design of Jasper Avenue in the realization that the urban priorities of future generations will be much different than they are today.

The above realization leads well into a discussion on 'trends' as Foucault understood them. Planning trends often apply practices and procedures with the interests of a particular stakeholder in mind (Elliott, 2008). Over time, the failures of this trend are realized, and so planners are pushed in the direction of a different trend in the hope of appeasing a newly prioritized interest (Elliott, 2008). Trends are a particularly tricky conundrum in planning, as the physical infrastructure created during a planning trend will continue to impact the city long after the trend has run its course (Elliott, 2008). It is this system of trends in planning that saw Jasper Avenue as the vibrant heart of downtown Edmonton at the beginning of the 20th century, then to the automobile-focused street of its current iteration. Planning trends will see Jasper Avenue in a configuration that cannot be imagined in one hundred, or perhaps even one thousand years from today. Trends in planning also do not quickly leave the public consciousness when the newest one appears on the scene; it is possible that the current friction between those who wish to see Jasper Avenue remain as it is and those who wish to reinvent the street is a result of both the planning profession and regular citizens undergoing a change in current predominant trends in urban street design. Only time will tell if our current placemaking trend is as effective at city building 
as we currently believe it to be. The positives from the Experience Jasper Avenue pilot project were highlighted almost three years later during the early stages of construction for the final design (Stolte, 2019). In the article, the massive increase to the available public space along the street is noted as an improvement by the public (Stolte, 2019). The increase in greenery provided by the addition of street trees is another commonly stated bonus (Stolte, 2019). While traffic impacts along the extent of the pilot project and a slight decrease in available street parking were observed from the removal of the two outside lanes on Jasper Avenue, these impacts were minimal and the benefit of increased pedestrian comfort and functionality far outweighed the seconds lost to automobile transportation (Stolte, 2019). While some Edmontonians commuting from their far-flung suburban houses did not appreciate the increase in commute time to their downtown offices, the neighbouring communities surrounding the Experience Jasper Avenue pilot project welcomed the changes to the public realm, as they provided a direct benefit to the amenities of their neighbourhoods (Stolte, 2019). Perhaps most importantly, the Experience Jasper Avenue pilot project began a conversation in the entire City of Edmonton around the current state of Jasper Avenue and what the future holds for our main street (Simons, 2017).

Areas for improvement in the final design of the project were also investigated by the news media (Gunter, 2017; Simons, 2017). The build out of the pilot project infrastructure was subpar, with the street trees dying in their planters due to lack of water and the temporary bollards being blown over in stiffwinds (Gunter, 2017). Of course, the temporary nature of the pilot project was a necessity, as every piece of infrastructure had to be able to be moved at a moment's notice in case of some unforeseen safety or other liability issue. Unfortunately, the extremely temporary nature of the Experience Jasper Avenue pilot project, such as sidewalk extensions being constructed out of rather unsightly asphalt, led to unaware citizens misunderstanding the pilot project as the finished product, and contributed to the overall negative reaction to the pilot project by a majority of
Edmontonians (Gunter, 2017; Simons, 2017). The section of Jasper Avenue on which the pilot project was constructed is not currently a destination for most Edmontonians, with the primary nearby use being residential apartments and condominiums. There are currently very few unique activities for citizens to engage, and this contributed to the relatively poor utilization of the placemaking infrastructure constructed as part of the pilot project, such as ping-pong tables and picnic benches (Simons, 2017).

\section{Semiotics}

The final theory that will be incorporated within the new framework proposed in this paper is Semiotics. Stroud and Jegels (2013) discuss an interpretation of semiotic landscapes as an understanding of the "situated social dynamics of multivocality in local places" (p. 179), specifically focusing on the impact of the "complex dynamics of place-making [on] our understanding of semiotic landscapes" (p. 180). The way in which one walks through a space is affected by infinite variables (Stroud \& Jegels, 2013). In other words, the local economic, social, and cultural feelings imparted by the physical characteristics of a landscape can impact the way a person moves through the space. These 'signs', though not actually physical signs, nonetheless direct the pedestrian from place to place, and can welcome or prohibit them, producing feelings of calm or distress. These feelings manifest themselves in "how residents organize their pathways and trajectories" (Stroud \& Jegels, 2013, p. 184) throughout their landscapes, as well as how "local residents (and even outsiders) narrate their different experiences" (Stroud \& Jegels, 2013, p. 184). As Jasper Avenue undergoes fundamental changes to its design and layout, planners can only hope that everyday citizens will notice the effect this has on their levels of comfort and willingness to use the placemaking elements designed into the landscape. Without enough cues, the citizens will see the same pedestrianunfriendly street and the desired conceptual shift of Jasper Avenue will never be actualized.

It is also important to fully understand the 
impact that the redesign of Jasper Avenue will have on people who are homeless who choose to congregate in the areas surrounding the main street. While Jasper Avenue does not currently have an unduly high population of people who are homeless living in or around the area, owing to the concentration of shelters and other facilities being located relatively far from the street, there are nonetheless people who are homeless who frequent the area. Wagner (2011) discusses how many spaces have been redesigned to "compel homeless people to leave city centres in a nonviolent way and without the use of force" (p. 236). This is an "act of power, of invisible coercion which only targets the most vulnerable category of the population" (Wagner, 2011, p. 236). Many places have had benches redesigned to prevent people from lying down and small spikes installed to prevent congregation on ledges (Wagner, 2011). Besides being physical deterrents, these are also psychological signs meant to signal the disapproval of people who might have no other choice but to sleep on a bench. The documents of the Imagine Jasper Avenue project do not include any mention of these elements to be included in the final construction, yet I do not believe anyone would be shocked were they to suddenly appear.

We have investigated enough source material and planning theories to understand that the Imagine Jasper Avenue project stands for much more than a redesign of Edmonton's main street. The design itself of the Imagine Jasper Avenue project is meant to send a signal to Edmontonians that Jasper Avenue is a place where pedestrians will be welcomed, prioritized, and valued. Imagine Jasper Avenue is also an extremely symbolic project, an initiative I believe is meant to signify the maturation of Edmonton, not only to the outside world but to Edmontonians themselves. Every world-class city has a worldclass main street: Chicago's Magnificent Mile; Paris' Champs-Elysées; New York's Broadway. While it is highly unlikely that Edmonton's Jasper Avenue will ever be in the same conversation as those streets, that does not mean that we should not strive to be in that conversation.

\section{Conclusion}

We now return to the question asked at the beginning of this paper: Why has there been a sudden renaissance of the ideas of placemaking in professional planning? Perhaps it is to define 'proper' urban development at a time of increasing urbanization worldwide. Or maybe it is to defend our vibrant urban neighbourhoods in the face of redevelopment as did planning icon Jane Jacobs. In any case, planning theorists can develop a clearer answer by exploring the larger trends surrounding the informal and formal history and culture of placemaking, and tracking its trends from the conceptualization of Planning and Design, the theories of Michel Foucault, and Semiotics, respectively, to the modern context.

Approaching placemaking from the viewpoint of Planning as Design proposes that the current state of Jasper Avenue - that is, an entirely automobile dominated space - has been rejected by planners and Edmontonians in favour of a street that more appropriately functions as a pedestrian-oriented place. Looking through the lens of Michel Foucault suggests that citizen stakeholders, empowered by the rise of poststructuralism in planning of the 21 st century, have rejected the current undesirable physical layout of Jasper Avenue that was forced into existence by the topdown power dynamics of planning in the mid-20th century. Exploring the topic through Semiotics indicates that the economic, social, and cultural changes of Edmonton require that Jasper Avenue be redesigned to reflect the maturation - for better or for worse - that Edmontonians see in themselves and in their city.

The case study and theories presented here attempt to rationalize placemaking in as normative a way as possible, understanding its themes and ideas through the lens of both renowned theorists and modernist design principles. Placemaking will continue to be a prevailing trend in the planning profession. The ideas of placemaking are fundamental to what it means to design successful, vibrant, and healthy cities. Placemaking has always been a major element of planning, it has just found itself a new, trendy identity. 


\section{References}

Brenner, N. (2004). New State Spaces: Urban Governance and the rescaling of Statehood. Oxford: Oxford University Press.

Carmona, M., De Magalhães, C. \& Edwards, M. (2002). Stakeholder views on value and urban design. Journal of Urban Design, 7(2), 145-169. https://doi.org/10.1080/ 1357480022000012212

Cilliers, E. J. \& Timmermans, W. (2014). The importance of creative participatory planning in the public placemaking process. Environment and Planning B: Urban Analytics and City Science, 41(3), 413-429. https://doi.org/10.1068/b39098

City of Edmonton. (n.d.). Experience Jasper Avenue. Retrieved from https://www. edmonton.ca/projects_plans/experiencejasper-avenue.aspx

City of Edmonton. (2017, July). Imagine Jasper Avenue / Experience Jasper Avenue: Project journey. Retrieved from https://www.edmonton.ca/documents/ ExperienceJasperAve_Journey_July2017. pdf

Elliott, D. L. (Eds.). (2008). A Better Way to Zone: Ten Principles to Create More Livable Cities. Washington, DC: Island Press.

Fontana, A. \& Pasquino, P. (1991) 'Truth and power', an interview with Foucault, in P. Rainbow (Ed.) The Foucault Reader. London: Penguin.

Foucault, M. (1988). The History of Sexuality. First Vintage Books ed. New York: Vintage Books.

Friedmann, J. (2010). Place and placemaking in cities: A global perspective. Planning Theory \& Practice, 11 (2), 149-165. https://doi. org/10.1080/14649351003759573

Gunter, L. (2017, August 24). Edmonton's Jasper Avenue streetscaping a disaster. Edmonton Sun, pg. A 1. Retrieved from https:// edmontonsun.com/2017/08/25/gunteredmontons-jasper-avenue-streetscapinga-disaster/wcm/5689e855-1 b54-4582aae7-5088eb 13e355
ISL Engineering and Land Services. (2017, June). Jasper Avenue streetscape - concept report. Retrieved from https://www. edmonton.ca/documents/RoadsTraffic/ IJA_14551_Final_Report_web.pdf

Jacobs, J. (1961). The Death and Life of Great American Cities. New York, NY: Random House, Inc.

Project for Public Spaces (PPS). (2014, March 19). Streets as places: How transportation can create a sense of community. Retrieved from https://www.pps.org/reference/ streets-as-places-how-transportation-cancreate-a-sense-of -community/

PPS. (2009a, December 31). About. Retrieved from https://www.pps.org/about/

PPS. (2009b, December 31 ) Streets as places: Streets are for... everything. Retrieved from https://www.pps.org/reference/streets-asplaces/

PPS. (2009c, December 31). What is placemaking? Retrieved from https://www. pps.org/reference/what_is_placemaking/ Richardson, T. (1995). Foucauldian discourse: Power and truth in urban and regional policy making. European Planning Studies, 4(3), 279-292. https://doi. org/10.1080/09654319608720346

Seamon, D. (2012). 'A jumping, joyous urban jumble': Jane Jacobs' Death and Life of Great American Cities as a phenomenology of urban place. The Journal of Space Syntax, 3(1), 139-149. Retrieved from http://joss.bartlett.ucl.ac.uk/journal/index. $\mathrm{php} /$ joss/article/view/121/pdf

Simons, P. (2017, August 23). Let's learn the right lessons from Experience Jasper Avenue. Edmonton Journal, pg. A1. Retrieved from http://edmontonjournal.com/news/localnews/paula-simons-lets-learn-the-rightlessons-from-experience-jasper-avenue

Stantec Consulting Ltd. (n.d.). Edmonton main streets guideline. Retrieved from https:// www.edmonton.ca/city_government/ documents/RoadsTraffic/MainStreet_ Guidelines_Feb2016.pdf 
Stolte, E. (2019, February 6). Jasper Avenue upgrade is worth a little pain for commuters. Edmonton Journal, pg. A 1. Retrieved from https://edmontonjournal.com/news/localnews/elise-stolte-jasper-avenue-upgradeis-worth-a-little-pain-for-commuters

Stroud, C. \& Jegels, D. (2014). Semiotic landscapes and mobile narrations of place: Performing the local. International Journal of the Sociology of Language, 228, 179-199. https://doi.org/10.1515/ijsl-2014-0010

Van Assche, K., Beunen, R., Duineveld, M., \& de Jong, H. (2013). Co-evolutions of planning and design: Risks and benefits of design perspectives in planning systems. Planning Theory, 12(2), 177- 198. https://doi. org/10.1177/1473095212456771

Wagner, A. (2011). French urban space management: A visual semiotic approach behind power and control. International Journal for the Semiotics of Law, 24(2), 227-241. https://doi.org/10.1007/ s 11196-010-9206-5 